\title{
Updated overview of evidence on optimal antithrombotic therapy in patients with atrial fibrillation undergoing percutanous coronary intervention
}

\author{
Marek Koziński ${ }^{1}$, Joanna Rejszel-Baranowska ${ }^{1}$, Elżbieta Młodawska², Jolanta M. Siller-Matula ${ }^{3,4}$, \\ Anna Tomaszuk-Kazberuk² \\ ${ }^{1}$ Department of Cardiology and Internal Medicine, Medical University of Gdansk, Gdynia, Poland \\ ${ }^{2}$ Department of Cardiology, Medical University of Bialystok, Bialystok, Poland \\ ${ }^{3}$ Department of Cardiology, Medical University of Vienna, Vienna, Austria \\ ${ }^{4}$ Department of Experimental and Clinical Pharmacology, Centre for Preclinical Research and Technology (CEPT), Medical University \\ of Warsaw, Warsaw, Poland
}

Adv Interv Cardiol 2020; 16, 2 (60): 127-137

DOI: https://doi.org/10.5114/aic.2020.96055

\begin{abstract}
A bstract
Selection of the optimal peri- and postprocedural antithrombotic regimen in patients with atrial fibrillation (AF) undergoing percutaneous coronary intervention (PCI) is a common clinical problem which may pose a challenge to medical practitioners. This systematic review summarizes the updated evidence on this topic. Non-vitamin K oral anticoagulants (NOACs) at standard doses are the preferred option in most of post $\mathrm{PCI}$ patients with $\mathrm{AF}$, except those few with a clear indication for a vitamin $\mathrm{K}$ antagonist (VKA). Reduced NOAC doses should be considered in dabigatran- or rivaroxaban-treated patients with a high bleeding risk, which prevail over concerns about stent thrombosis or ischemic stroke. There is insufficient evidence to favor one NOAC over another in this setting. In the early post stenting period, triple therapy comprising a NOAC, clopidogrel and aspirin is recommended. Timing of post $\mathrm{PCl}$ aspirin cessation should be based on a careful analysis of the bleeding and ischemic risk. There is only low quality evidence regarding the optimal approach to elective or urgent/emergency $\mathrm{PCl}$ procedures in patients requiring oral anticoagulation. It is suggested that there is no need of interruption of VKA and PCI procedure should be performed via radial artery access with a lower dose of unfractionated heparin. On the other hand, NOACs are usually stopped before elective PCIs, while urgent/emergency procedures may be performed with the addition of low-dose parenteral anticoagulation.
\end{abstract}

Key words: atrial fibrillation, percutaneous coronary intervention, non-vitamin $\mathrm{K}$ oral anticoagulants, vitamin $\mathrm{K}$ antagonist, anticoagulation.

\section{Introduction}

Optimal anticoagulant and antiplatelet treatment of patients with atrial fibrillation (AF) undergoing percutaneous coronary intervention $(\mathrm{PCI})$ still poses a great challenge to medical practitioners. The number of patients in need of such a treatment is ever-growing. AF affects approximately 33 million people worldwide, out of which $5-15 \%$ will undergo $\mathrm{PCl}$ at some point of their lives [1-3]. Clinicians need to face the problem of combining anticoagulant therapy, which is recommended for the prevention of ischemic stroke and systemic embolism in patients with $A F$, and dual antiplatelet therapy, which reduces the risk of stent thrombosis and subsequent coronary events. On the other hand, triple antithrombotic therapy, com- prising anticoagulant and dual antiplatelet therapy, is associated with a high risk of bleeding. Over the last few years, numerous clinical trials have been conducted with the aim of developing the best treatment strategies.

Based on the results of the after-mentioned trials, new guidelines on how to manage such complex cases have been developed. The aim of the present review is to provide an updated overview of evidence regarding the optimal peri- and postprocedural antithrombotic regimen in AF patients undergoing $\mathrm{PCl}$.

\section{Search strategy}

A systematic investigation of all published literature including oral presentations was conducted to minimize 
the risk of bias. A database search including PubMed, CENTRAL and Google Scholar databases, covering the period up to April 2020 was conducted by two independent investigators (M.K. and J.R.B.). We paid particular attention to randomized clinical trials, European and American guidelines and expert consensus documents. Proceedings of the Scientific Sessions of the American College of Cardiology (http://www.acc.org), American Heart Association (http://www.heart.org), European Society of Cardiology - ESC (http://www.escardio.org), Transcatheter Cardiovascular Therapeutics (http://www.tctmd.com) and EuroPCR (http://www.europcr.com) were also considered. The following keywords were applied: 'PCl', 'stenting', 'anticoagulant', 'anticoagulation', 'NOAC', 'DOAC' and 'warfarin'. References of retrieved studies, guidelines and position statements were searched manually for additional relevant publications.

\section{Periprocedural management during elective procedures}

According to the ESC guidelines on chronic coronary syndromes, for the patient treated with vitamin $\mathrm{K}$ antagonist (VKA) and admitted due to elective or emergency procedures, there is no need of VKA interruption. Radial artery access is preferred along with intraprocedural unfractionated heparin at a lower dose of 30-50 U/kg [4]. The uninterrupted strategy is supported by various studies. In the WOEST study, where 573 patients on VKA treatment underwent $\mathrm{PCl}$, in $43 \%$ the procedure was carried out without VKA interruption and in 57\% with VKA interruption plus low-molecular weight heparin bridging. At 30 days and at 1-year follow-up, the occurrence of bleeding events and major adverse cardiovascular events (MACE), including death, myocardial infarction, stroke, target vessel revascularization, and stent thrombosis was comparable in both groups [5].

In the AFCAS registry of 663 patients with AF who underwent $\mathrm{PCl}$ (for stable coronary artery disease (CAD) in approximately 50\%), at 3-month follow-up, both unadjusted major bleeding and MACE rates were significantly higher in the low-molecular-weight heparin (LMWH)-bridging group. After propensity score matching, and subsequent comparison of patients, in whom frequency of femoral access was similar, major bleeding was more frequent in the LMWH-bridging group at both 3 and 12 months, whereas MACE rates were comparable [6]. In a meta-analysis, uninterrupted oral anticoagulation (OAC) was found to be at least as safe as interrupted $\mathrm{OAC}$, and safer than interrupted $\mathrm{OAC}$ with bridging strategy [7]. Although, it was shown that the incidence of both early (24-h) and late (30-day) radial artery occlusion was significantly higher in the ongoing warfarin group comparing to standard, intra-procedural unfractionated heparin (UFH) administration [8]. However, doses as low as $30-50 \mathrm{U} / \mathrm{kg}$ have been shown to be effective in preventing ischemic complications related to $\mathrm{PCl}$ [9].

Limited data are available for AF patients undergoing $\mathrm{PCl}$ while on NOAC. There is an inconsistency of the results reported with the two different NOACs (dabigatran and rivaroxaban). In the phase Ila, multicenter clinical trial of 50 patients undergoing elective $\mathrm{PCl}$, dabigatran appeared to provide insufficient anticoagulation and clinical outcomes tended to be higher in the dabigatran group [10]. Different results were obtained in another phase Ila, multicenter trial [11]. In the X-PLORER study, patients undergoing elective $\mathrm{PCl}$ and on dual antiplatelet therapy were randomized to a single dose of either rivaroxaban $10 \mathrm{mg}$, rivaroxaban $20 \mathrm{mg}$, rivaroxaban $10 \mathrm{mg}$ plus intravenous bolus of UFH, or standard UFH. In all groups receiving rivaroxaban, coagulation was effectively suppressed, comparably to standard UFH. No patients in the three rivaroxaban arms required bail-out antithrombotic medication and/or had clinical signs of catheter-related thrombosis. No significant bleeding was observed in either group up to 30 days after $\mathrm{PCl}$.

According to the ESC guidelines on chronic coronary syndromes (CCS), it is recommended that NOAC therapy is stopped for $12-48 \mathrm{~h}$ before elective $\mathrm{PCl}$, depending on renal function and the particular NOAC regimen [4]. Radial artery access is preferred along with intraprocedural unfractionated heparin at a standard dose (70-100 U/kg). Pre-treatment with aspirin $75-100 \mathrm{mg}$ daily is recommended, and clopidogrel (300-600 mg loading dose if not on long-term maintenance therapy) is recommended in preference to prasugrel or ticagrelor. VKA-treated patients receiving aspirin and clopidogrel post- $\mathrm{PCl}$ should have a target international normalized ratio in the range of 2.0-2.5, aiming for high time in therapeutic range (> 70\%).

Periprocedural management during urgent and emergency procedures

No randomized trials have specifically studied periprocedural management in anticoagulated patients developing an acute coronary syndrome (ACS) and undergoing acute angiography with or without $\mathrm{PCl}$. According to "2018 Joint European consensus document on the management of antithrombotic therapy in atrial fibrillation", patients with AF taking OAC presenting with ACS and/ or undergoing percutaneous cardiovascular interventions should receive aspirin immediately $(150-300 \mathrm{mg}$ oral loading dose) [12, 13]. Anticoagulated patients undergoing primary $\mathrm{PCl}$ should receive additional low-dose parenteral anticoagulation regardless of the timing of the last dose of OAC (VKA or NOAC) (e.g. enoxaparin $0.5 \mathrm{mg} / \mathrm{kg}$ i.v. or UFH $60 \mathrm{IU} / \mathrm{kg}$ ). In patients on VKA and international normalized ratio (INR) value $>2.5$, it is suggested not to administer additional intraprocedural UFH [14].

To reduce the risk of bleeding there is a possibility to postpone the administration of $\mathrm{P} 2 \mathrm{Y} 12$ inhibitors to 
the time of $\mathrm{PCl}$, when the anatomy of coronary artery is known [14]. The P2Y12 inhibitor of choice is clopidogrel with $600 \mathrm{mg}$ loading dose [14]. Prasugrel and ticagrelor are not routinely recommended in anticoagulated patients due to their increased bleeding risk $[14,15]$. The radial approach is strongly recommended [16].

It is worth mentioning that a big discussion concerning dual therapy over triple therapy does not concern periprocedural management during coronary procedures as the majority of them were done on two antiplatelet agents.

\section{Post PCI therapy with VKAs}

Trials with VKAs which compared double versus triple therapy in AF patients undergoing PCI are the ISAR-TRIPLE trial (Triple Therapy in Patients on Oral Anticoagulation After Drug Eluting Stent Implantation) [17] and the WOEST trial (What Is the Optimal Antiplatelet \& Anticoagulant Therapy in Patients With Oral Anticoagulation and Coronary Stenting) [5].

In the ISAR-TRIPLE trial, patients treated with OAC were randomized to either 6 weeks or 6 months of DAPT (OAC plus clopidogrel) after PCI and DES (drug-eluting stent) implantation (one-third with an ACS) [17]. The main finding is that there was no difference in major bleeding events between patients treated with a 6-week or 6-month duration of clopidogrel. The authors explained that it might be due to the fact that approximately one-half of all bleeding events occurred in the first 6 weeks after $\mathrm{PCl}$, when both groups received the same therapy consisting of aspirin, clopidogrel, and OAC. There was no extra risk of the composite ischemic endpoint with shorter duration therapy and the rate of stroke was comparable in both groups.

The WOEST trial, despite the small sample size (573 patients), provided randomized evidence that the early discontinuation of aspirin reduces bleeding in comparison to triple therapy [5]. The trial found a $64 \%$ relative decrease in minor bleeding episodes without increase in ischemic events. The WOEST trial contributed to initiation of multiple trials of aspirin-free strategies in $\mathrm{PCl}$. What is more, in light of the results of the WOEST trial, the 1-year duration of triple therapy has been questioned, and the standard duration of triple therapy has become shorter.

\section{Post PCI therapy with NOACs}

The PIONEER AF PCl trial (Open-Label, Randomized, Controlled, Multicenter Study Exploring Two Treatment Strategies of Rivaroxaban and a Dose-Adjusted Oral Vitamin K Antagonist Treatment Strategy in Subjects with Atrial Fibrillation who Undergo Percutaneous Coronary Intervention) compared 3 treatment strategies after PCI in 2,124 patients with AF: a low-dose rivaroxaban (15 mg once daily - OD) plus clopidogrel, a very low-dose rivaroxaban (2.5 mg (BID) twice daily) plus aspirin and clopi- dogrel, and control triple therapy group with a VKA plus aspirin with clopidogrel [18]. It is important to realize that doses of rivaroxaban used in the PIONEER AF PCI trial do not represent the approved doses for stroke prevention in AF. They were chosen based on dose-finding investigations. The clinically significant bleeding (bleeding requiring medical attention) at 12 months was reduced by both rivaroxaban-based strategies compared with the control group. The efficacy in the prevention of cardiovascular events was similar for all study groups, but the power was low for ischemic endpoints. In the PIONEER AF PCI trial, aspirin was dropped at the investigator's discretion, most patients received triple therapy $\geq 6$ months. Variable duration of dual therapy in the $2.5 \mathrm{mg}$ BID (twice daily) rivaroxaban triple therapy group was 1,6 , or 12 months according to the physician's choice.

Another trial, RE-DUAL PCI (Randomized Evaluation of Dual Antithrombotic Therapy with Dabigatran versus Triple Therapy with Warfarin in Patients with Nonvalvular Atrial Fibrillation Undergoing Percutaneous Coronary Intervention) was designed to compare the safety of using different doses of dabigatran (110 mg and $150 \mathrm{mg}$ ) in combination with clopidogrel and triple antithrombotic therapy with warfarin [19]. In the triple antithrombotic therapy group, aspirin was discontinued after 1 month in patients who received a bare-metal stent (17\%) and after 3 months in patients who received a DES (83\%). Dual therapy was continued for at least 12 months. Ticagrelor in the RE-DUAL PCI was used in $12 \%$. The risk of major or clinically relevant non-major bleeding in the $110 \mathrm{mg}$ and $150 \mathrm{mg}$ dabigatran group was significantly lower than in the warfarin group. These results did not differ between stable CAD or ACS group or whether clopidogrel or ticagrelor was used. It should be noted, however, that it is impossible to state clearly if the reduction in the risk of bleeding among patients treated with dabigatran was related to the effect of the drug or the non-use of aspirin. There were no significant differences between the two dabigatran-based arms and the warfarin-based strategy when evaluating the risk of death, thromboembolic events and non-planned revascularization, both in ACS and elective $\mathrm{PCI}$ populations.

The AUGUSTUS trial (An Open-label, 2 Factorial, Randomized Controlled, Clinical Trial to Evaluate the Safety of Apixaban vs. Vitamin K Antagonist and Aspirin vs. Aspirin Placebo in Patients With Atrial Fibrillation and Acute Coronary Syndrome or Percutaneous Coronary Intervention) showed that the safest combination was apixaban and placebo in addition to P2Y12 inhibitor, most frequently clopidogrel. Apixaban $5 \mathrm{mg}$ BID was associated with significantly less major or clinically relevant non-major bleeding than VKA [20]. The study also proved that aspirin, compared with placebo, was associated with significantly more bleedings. Apart from this the authors showed a reduced combined endpoint composed of 
death and hospitalization. It is worth remembering that the used dose of $5 \mathrm{mg}$ BID is a basic regular dose for stroke protection in AF patients. Nevertheless there was a non-significant increase in stent thrombosis events and myocardial infarction with placebo compared to the arm with aspirin. However, the trial was not powered to assess differences in these events between the investigated groups. One of the limitation of the study is that randomization was allowed within 14 days after ACS/PCI and in practice the patients were enrolled at a median of 6 days from ACS and/or $\mathrm{PCl}$, which suggests that most patients in the trial had at least short-term aspirin use before randomization. In the RE-DUAL PCI [19] and PIONEER AF [18] trials patients were enrolled within 120 and $72 \mathrm{~h}$ after $\mathrm{PCl}$, respectively. There is one more significant difference between these three trials: in the AUGUSTUS trial, 23.9\% of patients with ACS were medically managed, $37.3 \%$ with ACS were treated with $\mathrm{PCl}$ and $38.8 \%$ were enrolled after elective $\mathrm{PCl}$. What does it mean for our patients? The RE-DUAL PCI and the PIONEER AF results describe $\mathrm{PCI}$ population, while the AUGUSTUS results are more applicable to medically managed ACS population. Besides, time in therapeutic range (TTR) of warfarin may play an important role in the comparison between warfarin and NOAC treated populations. Mean TTR in the AUGUSTUS trial was 59\% [20], while in the RE-DUAL PCI and the PIONEER AF trials TTR was $64-65 \%[18,19]$. The higher quality of TTR the more robust safety results. Also the follow-up time in the AUGUSTUS trial was shorter than in the PIONEER-AF PCI, the RE-DUAL PCI and ENTRUST AF-PCI trials (6 months vs. 12 months) [18-21].

In the ENTRUST AF-PCI trial, patients were randomly assigned from $4 \mathrm{~h}$ to 5 days after $\mathrm{PCl}$ to either edoxaban (60 mg OD) plus a P2Y12 inhibitor for 12 months or a vitamin $\mathrm{K}$ antagonist (VKA) in combination with a P2Y12 inhibitor and aspirin (100 mg OD, for 1-12 months). The edoxaban dose was reduced to $30 \mathrm{mg}$ if at least one of the following factors (creatinine clearance $15-50 \mathrm{ml} / \mathrm{min}$, bodyweight $\leq 60 \mathrm{~kg}$, or concomitant use of specified potent P-glycoprotein inhibitors) was present. The study showed that double therapy with edoxaban is non-inferior to combined therapy with VKA in terms of major and non-major clinically relevant bleeding events. Main efficacy outcome which was composed of cardiovascular death, stroke, systemic embolism, myocardial infarction and stent thrombosis did not differ between the strategy based on edoxaban and warfarin. Although the study was not designed to test either superiority or non-inferiority of edoxaban-based regimen vs VKA-based regimen in terms of the efficacy outcome [21].

Details regarding the design and results of landmark trials on the role of NOACs in AF patients treated with $\mathrm{PCl}$ are summarized in Table I. These randomized trials showed that double therapy with a P2Y12 inhibitor and NOAC is safer with respect to bleeding than triple therapy (including warfarin). However, none of these studies were sufficiently powered for efficacy and the populations studied were a mixture of stable CAD and ACS patients.

\section{Results of recent meta-analyses}

Two meta-analyses including the AUGUSTUS, ENTRUST AF-PCI, PIONEER AF-PCI, and RE-DUAL PCI studies found that dual when compared with triple antithrombotic therapy reduced the risk for major bleeding, without any impact on all-cause mortality and the risk of myocardial infarction $[22,23]$. Importantly, one of these papers also demonstrated that this benefit was counterbalanced by a significant increase in the risk of stent thrombosis (relative risk (RR) 1.59, 95\% confidence interval (Cl): 1.01-2.50) [22].

\section{Current recommendations}

Anticoagulants in AF patients have demonstrated superiority over aspirin monotherapy or clopidogrel-based DAPT for stroke prevention, and are therefore recommended for this indication [24].

Current ESC recommendations on CCS from 2019 (Table II) showed that in patients who are eligible for a NOAC, it is recommended that apixaban $5 \mathrm{mg}$ BID, dabigatran $150 \mathrm{mg} B \mathrm{DID}$, edoxaban $60 \mathrm{mg}$ OD, or rivaroxaban $20 \mathrm{mg}$ OD is used in preference to a VKA in combination with antiplatelet therapy (class of recommendation I, level of evidence A) [4]. In patients with a high bleeding risk, rivaroxaban $15 \mathrm{mg}$ OD should be considered in preference to rivaroxaban $20 \mathrm{mg}$ OD or dabigatran $110 \mathrm{mg}$ BID should be considered in preference to dabigatran $150 \mathrm{mg}$ BID for the duration of concomitant single or dual antiplatelet therapy (class of recommendation Ila, level of evidence B). Triple therapy with aspirin, clopidogrel and an OAC for $\geq 1$ month should be considered when the risk of stent thrombosis outweighs the bleeding risk, with the total duration $\leq 6$ months, decided according to assessment of these risks (class of recommendation Ila, level of evidence C) [4].

According to "2018 Joint European consensus document on the management of antithrombotic therapy in atrial fibrillation patients presenting with acute coronary syndrome and/or undergoing percutaneous cardiovascular interventions", triple therapy can be shortened to one month and then followed by dual therapy with OAC plus clopidogrel up to 12 months in patients with a high bleeding risk (estimated using the HAS-BLED score) [12]. Patients with a very high bleeding risk (e.g. recent bleeding event) can be treated with dual therapy (OAC plus clopidogrel) up to 3-6 months without a one-month triple therapy period. Time frames remain similar for AF patients presenting with elective $\mathrm{PCI}$ or ACS undergoing $\mathrm{PCl}$. However, in patients with non-ST-segment elevation acute coronary syndrome (NSTE-ACS) triple therapy should last 3 to 6 months, while in ST-segment elevation 


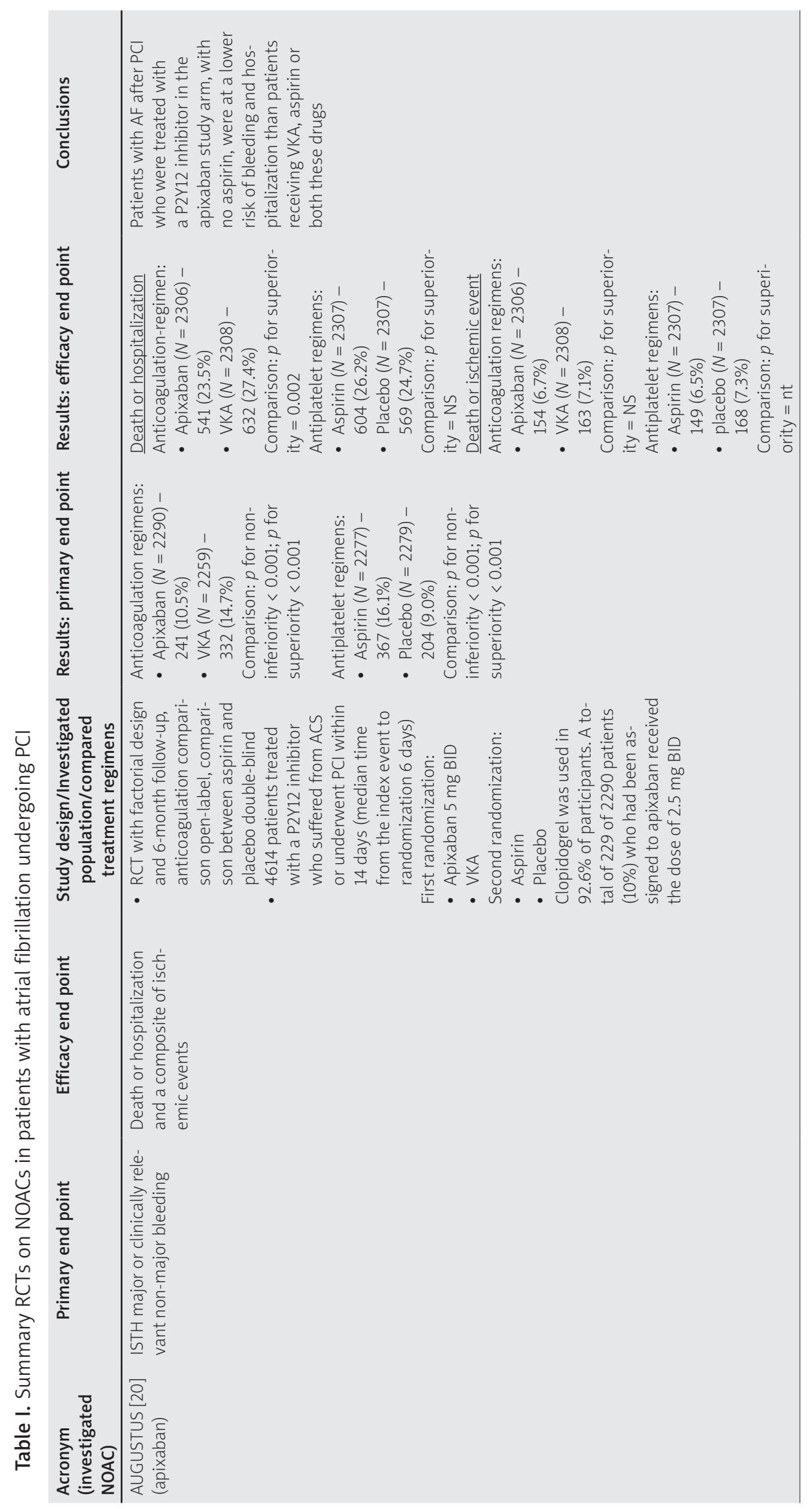




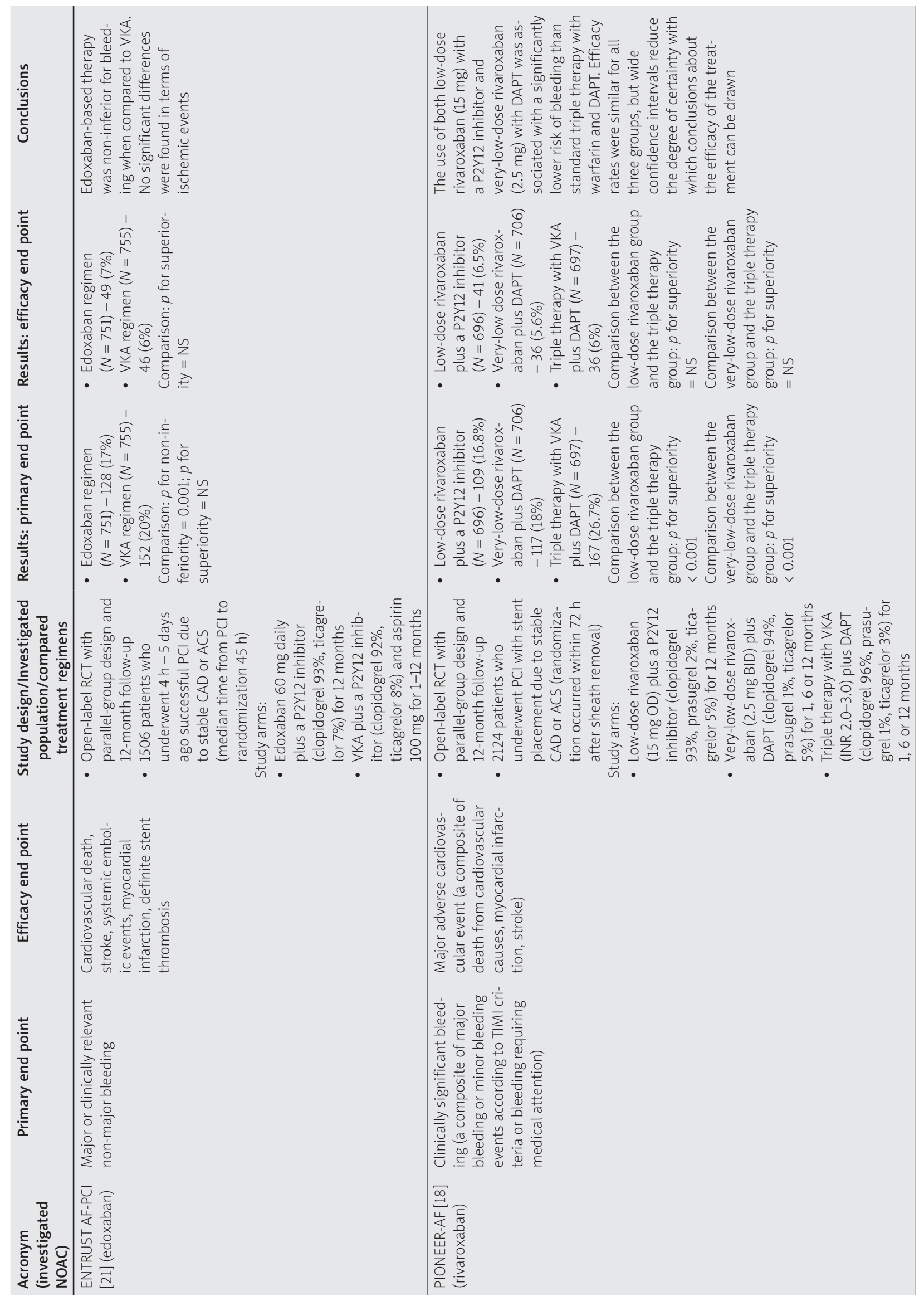




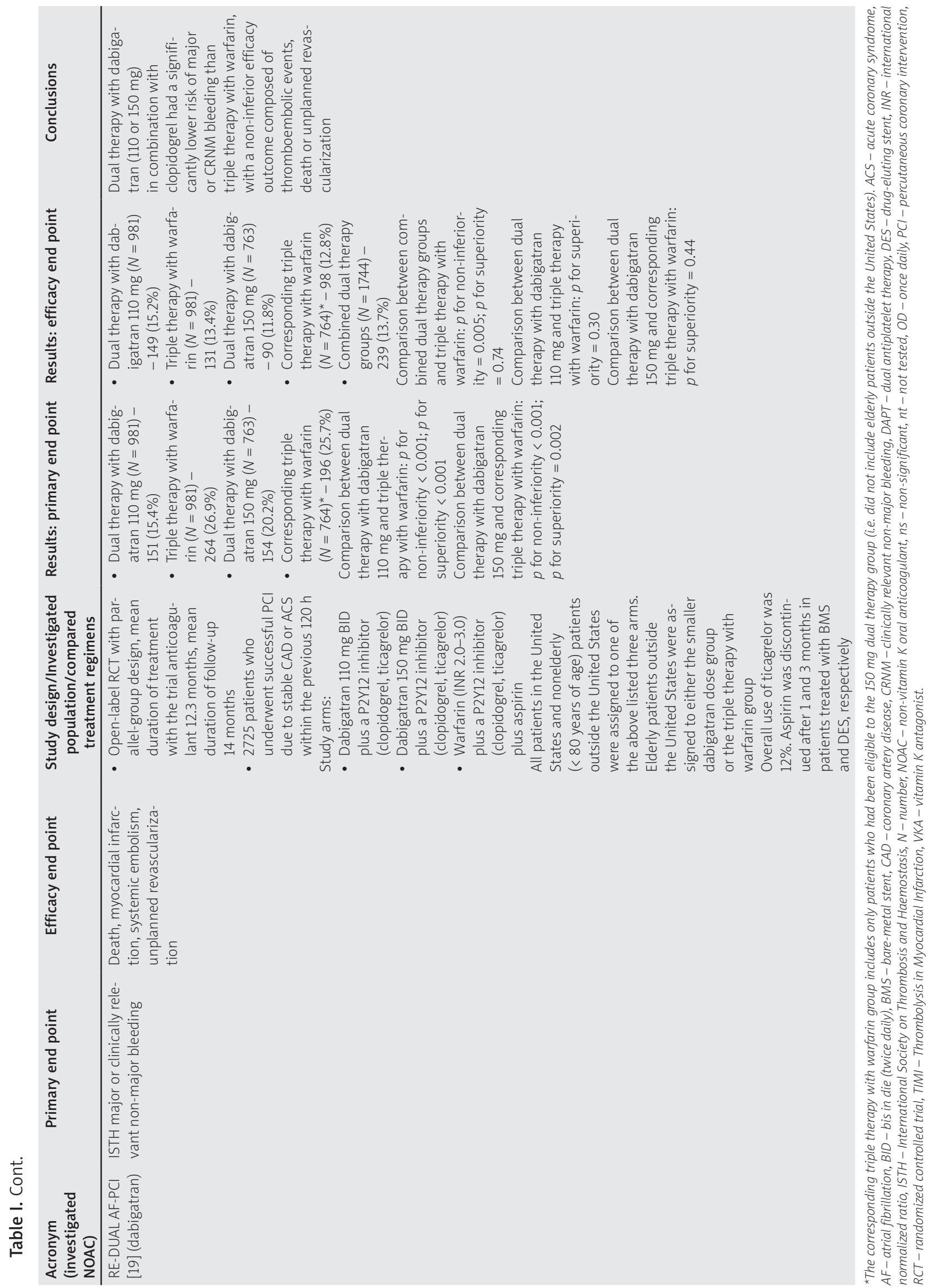


Table II. The ESC recommendations on antithrombotic therapy in patients with CCS and AF, including post-PCI recommendations [4]

\begin{tabular}{|c|c|c|}
\hline Recommendation & $\begin{array}{l}\text { Class of } \\
\text { recommendation }\end{array}$ & $\begin{array}{l}\text { Level of } \\
\text { evidence }\end{array}$ \\
\hline $\begin{array}{l}\text { When oral anticoagulation is initiated in a patient with AF who is eligible for a NOAC, a NOAC is recom- } \\
\text { mended in preference to a VKA }\end{array}$ & I & A \\
\hline $\begin{array}{l}\text { Long-term OAC therapy (NOAC or VKA with time in therapeutic range }>70 \% \text { ) is recommended in pa- } \\
\text { tients with AF and a } \mathrm{CHA}_{2} \mathrm{DS}_{2} \text {-VASc score } \geq 2 \text { in males and } \geq 3 \text { in females }\end{array}$ & 1 & $A$ \\
\hline $\begin{array}{l}\text { Long-term OAC therapy (NOAC or VKA with time in therapeutic range }>70 \% \text { ) should be considered in } \\
\text { patients with AF and a CHA } \mathrm{DS}_{2} \text {-VASc score of } 1 \text { in males and } 2 \text { in females }\end{array}$ & Ila & B \\
\hline $\begin{array}{l}\text { Aspirin } 75-100 \mathrm{mg} \text { daily (or clopidogrel } 75 \mathrm{mg} \text { daily) may be considered in addition to long-term OAC } \\
\text { therapy in patients with AF, history of } \mathrm{MI} \text {, and at high risk of recurrent ischemic events }{ }^{1} \text { who do not have } \\
\text { a high bleeding risk }\end{array}$ & $\| \mathrm{lb}$ & B \\
\hline $\begin{array}{l}\text { It is recommended that peri-procedural aspirin and clopidogrel are administered to patients undergoing } \\
\text { coronary stent implantation }\end{array}$ & I & $C$ \\
\hline $\begin{array}{l}\text { In patients who are eligible for a NOAC, it is recommended that a NOAC (apixaban } 5 \text { mg BID, dabigatran } \\
150 \mathrm{mg} \text { BID, edoxaban } 60 \mathrm{mg} \text { OD, or rivaroxaban } 20 \mathrm{mg} \text { OD) is used in preference to a VKA in combina- } \\
\text { tion with antiplatelet therapy }\end{array}$ & 1 & $A$ \\
\hline $\begin{array}{l}\text { When rivaroxaban is used and concerns about the high bleeding risk }{ }^{2} \text { prevail over concerns about stent } \\
\text { thrombosis } \mathrm{s}^{3} \text { ischemic stroke }{ }^{4} \text {, rivaroxaban } 15 \mathrm{mg} \text { OD should be considered in preference to rivarox- } \\
\text { aban } 20 \mathrm{mg} \text { OD for the duration of concomitant single or dual antiplatelet therapy }\end{array}$ & Ila & B \\
\hline $\begin{array}{l}\text { When dabigatran is used and concerns about the high bleeding risk }{ }^{2} \text { prevail over concerns about stent } \\
\text { thrombosis }{ }^{3} \text { or ischemic stroke }{ }^{4} \text {, dabigatran } 110 \mathrm{mg} \text { BID should be considered in preference to dabiga- } \\
\text { tran } 150 \text { mg b.i.d. for the duration of concomitant single or dual antiplatelet therapy }\end{array}$ & Ila & B \\
\hline $\begin{array}{l}\text { After uncomplicated } \mathrm{PCl} \text {, early cessation ( } \leq 1 \text { week) of aspirin and continuation of dual therapy with an } \\
\mathrm{OAC} \text { and clopidogrel should be considered if the risk of stent thrombosis }{ }^{3} \text { is low, or if concerns about the } \\
\text { bleeding risk prevail over concerns about the risk of stent thrombosis }{ }^{3} \text { irrespective of the type of stent } \\
\text { used }\end{array}$ & Ila & B \\
\hline $\begin{array}{l}\text { Triple therapy with aspirin, clopidogrel, and an OAC for } \geq 1 \text { month should be considered when the risk of } \\
\text { stent thrombosis }{ }^{3} \text { outweighs the bleeding risk, with the total duration ( } \leq 6 \text { months) decided according } \\
\text { to assessment of these risks and clearly specified at hospital discharge }\end{array}$ & Ila & C \\
\hline $\begin{array}{l}\text { In patients with an indication for a VKA in combination with aspirin and/or clopidogrel, the dose inten- } \\
\text { sity of the VKA should be carefully regulated with a target international normalized ratio in the range of } \\
2.0-2.5 \text { and with time in therapeutic range }>70 \%\end{array}$ & Ila & $B$ \\
\hline $\begin{array}{l}\text { Dual therapy with an OAC and either ticagrelor or prasugrel may be considered as an alternative to triple } \\
\text { therapy with an OAC, aspirin, and clopidogrel in patients with a moderate or high risk of stent thrombo- } \\
\text { sis }^{3} \text { irrespective of the type of stent used }\end{array}$ & $\mathrm{Ilb}$ & $C$ \\
\hline $\begin{array}{l}\text { The use of ticagrelor or prasugrel is not recommended as part of triple antithrombotic therapy with } \\
\text { aspirin and an OAC }\end{array}$ & III & $C$ \\
\hline $\begin{array}{l}\text { Concomitant use of a proton pump inhibitor is recommended in patients receiving aspirin monotherapy, } \\
\text { DAPT, or OAC monotherapy who are at high risk of gastrointestinal bleeding }\end{array}$ & I & $A$ \\
\hline
\end{tabular}

${ }^{1}$ Diffuse multivessel CAD with at least one of the following: diabetes mellitus requiring medication, recurrent MI, PAD, or CKD with eGFR 15-59 ml/min/1.73 m². 2 Prior history of intracerebral hemorrhage or ischemic stroke, history of other intracranial pathology, recent gastrointestinal bleeding or anemia due to possible gastrointestinal blood loss, other gastrointestinal pathology associated with an increased bleeding risk, liver failure, bleeding diathesis or coagulopathy, extreme old age or frailty, or renal failure requiring dialysis or with eGFR $<15 \mathrm{ml} / \mathrm{min} / 1.73 \mathrm{~m}^{2}$. ${ }^{3}$ Risk of stent thrombosis encompasses (i) the risk of thrombosis occurring and (ii) the risk of death should stent thrombosis occur, both of which relate to anatomical, procedural, and clinical characteristics. Risk factors for CCS patients include stenting of the left main stem, proximal LAD, or last remaining patent artery; suboptimal stent deployment; stent length > 60 mm; diabetes mellitus; CKD; bifurcation with two stents implanted; treatment of chronic total occlusion; and previous stent thrombosis on adequate antithrombotic therapy. ${ }^{4} \mathrm{Congestive} \mathrm{HF}$, hypertension, age $\geq 75$ years (2 points), diabetes, prior stroke/transient ischemic attack/embolus (2 points), vascular disease (CAD on imaging or angiography, prior MI, PAD, or aortic plaque), age 65-74 years, and female sex. AF - atrial fibrillation, BID - bis in die (twice daily). CAD - coronary artery disease, CCS - chronic coronary syndrome, CKD - chronic kidney disease, DAPT - dual antiplatelet therapy, eGFR - estimated glomerular filtration rate, ESC - European Society of Cardiology, HF - heart failure, $\angle A D$ - left anterior descending artery, MI-myocardial infarction, NOAC-non-vitamin K oral anticoagulant, OAC - oral anticoagulant, OD - once daily, PAD - peripheral artery disease, $\mathrm{PCl}$ - percutaneous coronary intervention, VKA - vitamin K antagonist.

myocardial infarction (STEMI) patients, 6 months [12]. A different point of view is presented in the American consensus [25]. Duration of the triple therapy is recommended only for peri-PCl time, or 1 month in patients at high thrombotic risk and low bleeding risk.

Summarizing, a North American perspective suggests that the triple therapy should be used only during in-hospital stay followed by OAC and clopidogrel for
6 to 12 months depending on the bleeding risk and this should be the way of treatment of the vast majority of all patients treated with $\mathrm{PCl}$, including ACS patients [25]. So the American consensus goes along with the RE-DUAL PCI, PIONEER AF-PCI and AUGUSTUS trials results [18-20]. While the European perspective is still more conservative and suggests that triple therapy should be stopped at discharge, 1 month, or 3 to 6 months depend- 
ing on the individual thrombotic and bleeding profile [12]. According to the European consensus, patients with a prevailing thrombotic risk (high SYNTAX score in elective $\mathrm{PCl}$, high GRACE score > 140 in ACS, stenting of the left main, proximal LAD (left anterior descending artery), proximal bifurcation, recurrent myocardial infarction, stent thrombosis etc.) should be treated with triple therapy even up to 6 months. Suboptimal stent placement may also increase the risk of ischemic events. In such cases, assessment with imaging technique is strongly recommended. Generally, experts on both sides of the Atlantic Ocean agree that triple antithrombotic therapy should be as short as possible [26].

Additionally, the European experts express opinions that i) In view of the superior anti-restenotic efficacy and no signal of a higher thrombotic risk of new-generation DES it is recommended that patients with AF undergoing $\mathrm{PCl}$ should be treated with new generation DES; ii) Choice of DAPT duration should not be differentiated based on whether the stent implanted at time of $\mathrm{PCl}$ is a DES or bare-metal stent; and iii) Patients requiring oral anticoagulation should not receive bioresorbable vascular scaffolds [12].

In the long-term treatment, aspirin 75-100 mg daily (or clopidogrel $75 \mathrm{mg}$ daily) may be considered in addition to OAC therapy in patients with AF, history of myocardial infarction, and at high risk of recurrent ischemic events. This strategy is recommended in patients who do not have a high bleeding risk (class of recommendation $\mathrm{Ilb}$, level of evidence B). Dual therapy with an OAC and either ticagrelor or prasugrel may be considered as an alternative to triple therapy with an OAC, aspirin, and clopidogrel in patients with a moderate or high risk of stent thrombosis, irrespective of the type of stent used (class of recommendation $\mathrm{Ilb}$, level of evidence $\mathrm{C}$ ). The use of ticagrelor or prasugrel is not recommended as part of triple antithrombotic therapy with aspirin and an OAC (class III, level of evidence $C$ ) because of the high bleeding risk [4].

In Figure 1, we propose an algorithm which combines both European and American perspectives.

\section{Gaps in the evidence}

There are several gaps in the evidence that warrant exploration. Firstly, optimal duration of periprocedural therapy with aspirin in $\mathrm{PCl}$-treated $\mathrm{AF}$ patients remains controversial and the risk of ischemic coronary events (e.g. stent thrombosis) related to early aspirin cessation cannot be neglected. Secondly, optimal management of patients on NOAC treatment who require urgent or emergency $\mathrm{PCl}$ needs to be investigated. Finally, safety and efficacy of dual therapy with a NOAC and ticagrelor or prasugrel should be studied.
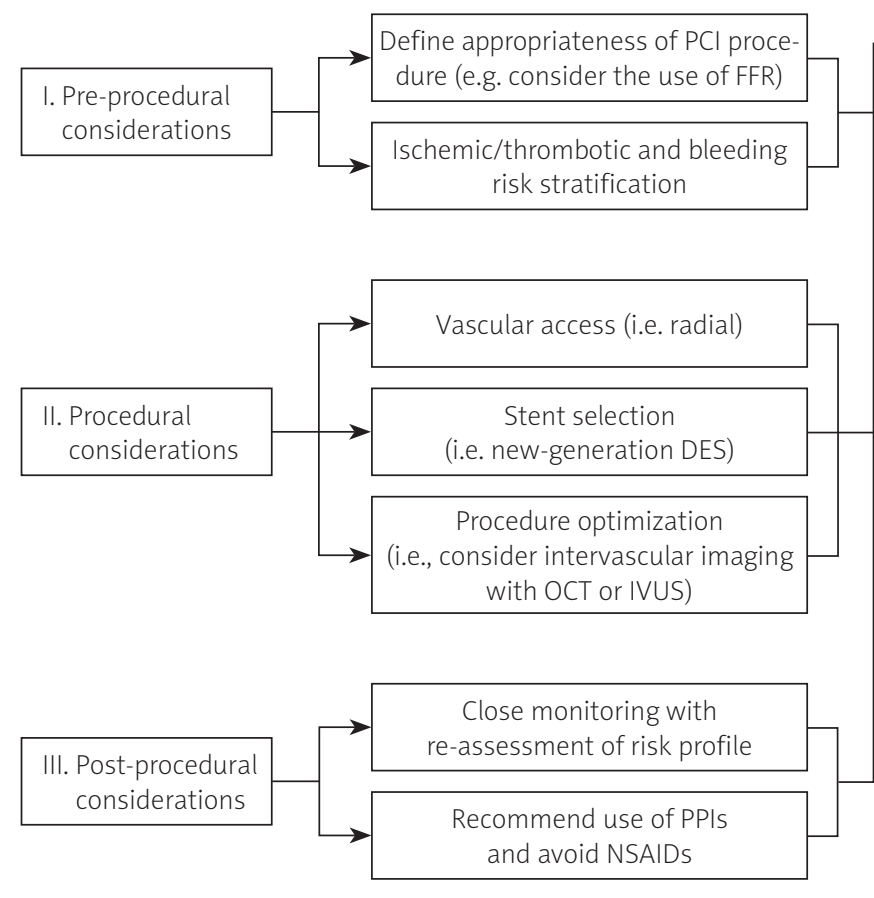

Antithrombotic management

OAC:

- A NOAC should be preferred in most patients and used at established stroke prevention doses; lower doses are not recommended unless specifically tested

- If VKA is chosen, maintain INR at the lower end of the therapeutic range (e.g. 2.0-2.5)

- Maintain OAC life-long

APT:

- Aspirin in the peri-PCl phase and continued through hospital discharge

- Clopidogerel is the P2Y $Y_{12}$ inhibitor of choice; ticagrelor may be a reasonable alternative in high ischemic and low bleeding risk patients; avoid prasugrel

- Discontinue SAPT at 1 year in most patients; consider earlier SAPT discontinuation (e.g. 6 months) in patients at low ischemic or high bleeding risks and prolonging SAPT (> 1 year) for select patients with high ischemic and low bleeding risks

Strategy (double vs. triple therapy):

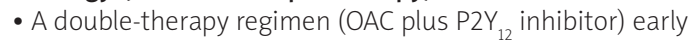
after hospital discharge for most patients

- Consider triple-therapy by extending aspirin use for a limited period of time (e.g. 3-6 months) only in patients at high ischemic and low bleeding risks

Figure 1. Algorithm for the management of patients with atrial fibrillation requiring oral anticoagulation undergoing PCI. Modified based on Angiolillo et al. [25]

$A P T$ - antiplatelet therapy, DES - drug-eluting stent, FFR - fractional flow reserve, INR - international normalized ratio, IVUS - intravascular ultrasound, NOAC - non-vitamin K antagonist oral anticoagulant, NSAID - nonsteroidal anti-inflammatory drug, OCT - optical coherence tomography, PCI - percutaneous coronary intervention, PPI - proton pump inhibitor, SAPT - single antiplatelet therapy, VKA - vitamin K antagonist. 


\section{Conclusions}

NOACs at standard doses are the preferred option in most of post $\mathrm{PCl}$ patients with $\mathrm{AF}$, except those with a clear indication for VKAs (i.e. patients with prosthetic heart valve or with mitral stenosis) [27]. Reduced NOAC doses should be considered in dabigatran- or rivaroxaban-treated patients with a high bleeding risk, which prevail over concerns about stent thrombosis or ischemic stroke. There is insufficient evidence to favor one NOAC over another in this setting. In the early post stenting period, triple therapy comprising a NOAC, clopidogrel and aspirin is recommended. Timing of post $\mathrm{PCl}$ aspirin cessation should be based on a careful analysis of the bleeding and ischemic risk. Depending on the result, all very early ( $\leq 1$ week), intermediate (at 1-3 months) and relatively late (at 6 months) aspirin discontinuation may be considered. There is only low quality evidence regarding the optimal approach to elective or urgent/emergency $\mathrm{PCl}$ procedures in patients requiring $\mathrm{OAC}$. Undoubtedly, all $\mathrm{AF}$ patients undergoing coronary stenting should be treated with a new generation DES. It is suggested that there is no need of interruption of VKA and $\mathrm{PCl}$ procedure should be performed via radial artery access with a lower dose of unfractionated heparin. On the other hand, NOACs are stopped before elective $\mathrm{PCls}$, while emergency procedures may be performed with the addition of low-dose parenteral anticoagulation.

\section{Conflict of interest}

Marek Koziński received speaker fees from Bayer, Boehringer-Ingelheim and Pfizer. Jolanta Maria SillerMatula received speaker fees from Bayer, Bristol Myers Squibb and Daiichi Sankyo. Anna Tomaszuk-Kazberuk received speaker and consultation fees from Boehringer-Ingelheim and consultation fee from Bayer. Other authors disclosed that they have no significant relationships with or financial interests in any commercial companies related to this review.

\section{References}

1. Virani SS, Alonso A, Benjamin EJ, et al. Heart Disease and Stroke Statistics-2020 Update: A Report From the American Heart Association Circulation 2020; 141: e139-596.

2. Kralev S, Schneider K, Lang S, et al. Incidence and severity of coronary artery disease in patients with atrial fibrillation undergoing first-time coronary angiography. PLoS One 2011; 6: e24964.

3. Chugh SS, Havmoeller R, Narayanan K, et al. Worldwide epidemiology of atrial fibrillation: a global burden of disease 2010 study. Circulation 2014; 129: 837-47.

4. Knuuti J, Wijns W, Saraste A, et al. 2019 ESC Guidelines for the diagnosis and management of chronic coronary syndromes. Eur Heart J 2020; 41: 407-77.

5. Dewilde WJ, Oirbans T, Verheugt FW, et al. Use of clopidogrel with or without aspirin in patients taking oral anticoagulant therapy and undergoing percutaneous coronary intervention: an open-label, randomised, controlled trial. Lancet 2013; 381: 1107-15.
6. Kiviniemi T, Airaksinen KE, Rubboli A, et al. Bridging therapy with low molecular weight heparin in patients with atrial fibrillation undergoing percutaneous coronary intervention with stent implantation: the AFCAS study. Int J Cardiol 2015; 183: 105-10.

7. Kowalewski M, Suwalski P, Raffa GM, et al. Meta-analysis of uninterrupted as compared to interrupted oral anticoagulation with or without bridging in patients undergoing coronary angiography with or without percutaneous coronary intervention. Int J Cardiol 2016; 223: 186-94.

8. Pancholy SB, Ahmed I, Bertrand OF, Patel T. Frequency of radial artery occlusion after transradial access in patients receiving warfarin therapy and undergoing coronary angiography. Am J Cardiol 2014; 113: 211-4.

9. Niccoli G, Banning AP. Heparin dose during percutaneous coronary intervention: how low dare we go? Heart 2002; 88: 331-4.

10. Vranckx P, Verheugt FW, de Maat MP, et al. A randomised study of dabigatran in elective percutaneous coronary intervention in stable coronary artery disease patients. Eurolntervention 2013; 8: 1052-60.

11. Vranckx P, Leebeek FW, Tijssen JG, et al. Peri-procedural use of rivaroxaban in elective percutaneous coronary intervention to treat stable coronary artery disease. The X-PLORER trial. Thromb Haemost 2015; 114: 258-67.

12. Lip GYH, Collet JP, Haude M, et al. 2018 Joint European consensus document on the management of antithrombotic therapy in atrial fibrillation patients presenting with acute coronary syndrome and/or undergoing percutaneous cardiovascular interventions: a joint consensus document of the European Heart Rhythm Association (EHRA), European Society of Cardiology Working Group on Thrombosis, European Association of Percutaneous Cardiovascular Interventions (EAPCI), and European Association of Acute Cardiac Care (ACCA) endorsed by the Heart Rhythm Society (HRS), Asia-Pacific Heart Rhythm Society (APHRS), Latin America Heart Rhythm Society (LAHRS), and Cardiac Arrhythmia Society of Southern Africa (CASSA). Europace 2019; 21: 192-3.

13. Ibanez B, James S, Agewall S, et al. 2017 ESC Guidelines for the management of acute myocardial infarction in patients presenting with ST-segment elevation: The Task Force for the management of acute myocardial infarction in patients presenting with ST-segment elevation of the European Society of Cardiology (ESC). Eur Heart J 2018; 39: 119-77.

14. Roffi M, Patrono C, Collet JP, et al. 2015 ESC Guidelines for the management of acute coronary syndromes in patients presenting without persistent ST-segment elevation: Task Force for the Management of Acute Coronary Syndromes in Patients Presenting without Persistent ST-Segment Elevation of the European Society of Cardiology (ESC). Eur Heart J 2016; 37: 267-315.

15. Sarafoff N, Martischnig A, Wealer J, et al. Triple therapy with aspirin, prasugrel, and vitamin $\mathrm{K}$ antagonists in patients with drug-eluting stent implantation and an indication for oral anticoagulation. J Am Coll Cardiol 2013; 61: 2060-6.

16. Valgimigli M, Gagnor A, Calabró P, et al. Radial versus femoral access in patients with acute coronary syndromes undergoing invasive management: a randomised multicentre trial. Lancet 2015; 385: 2465-76.

17. Fiedler KA, Maeng M, Mehilli J, et al. Duration of triple therapy in patients requiring oral anticoagulation after drug-eluting stent implantation: the ISAR-TRIPLE Trial. J Am Coll Cardiol 2015; 65: 1619-29. 
18. Gibson CM, Mehran R, Bode C, et al. Prevention of bleeding in patients with atrial fibrillation undergoing $\mathrm{PCl}$. N Engl J Med 2016; 375: 2423-34.

19. Cannon CP, Bhatt DL, Oldgren J, et al. Dual antithrombotic therapy with dabigatran after $\mathrm{PCl}$ in atrial fibrillation. $\mathrm{N}$ Engl J Med 2017; 377: 1513-24.

20. Lopes RD, Heizer G, Aronson R, et al. Antithrombotic therapy after acute coronary syndrome or $\mathrm{PCl}$ in atrial fibrillation. $\mathrm{N}$ Eng J Med 2019; 380: 1509-24.

21. Vranckx P, Valgimigli M, Eckardt L, et al. Edoxaban-based versus vitamin $\mathrm{K}$ antagonist-based antithrombotic regimen after successful coronary stenting in patients with atrial fibrillation (ENTRUST-AF PCI): a randomised, open-label, phase 3b trial. Lancet 2019; 394: 1335-43.

22. Gargiulo G, Goette A, Tijssen J, et al. Safety and efficacy outcomes of double vs. triple antithrombotic therapy in patients with atrial fibrillation following percutaneous coronary intervention: a systematic review and meta-analysis of non-vitamin $\mathrm{K}$ antagonist oral anticoagulant-based randomized clinical trials. Eur Heart J 2019; 40: 3757-67.

23. Khan SU, Osman M, Khan MU, et al. Dual versus triple therapy for atrial fibrillation after percutaneous coronary intervention: a systematic review and meta-analysis. Ann Intern Med 2020; 172: 474-83.

24. Kirchhof P, Benussi S, Kotecha D, et al. 2016 ESC Guidelines for the management of atrial fibrillation developed in collaboration with EACTS. Eur Heart J 2016; 37: 2893-962.

25. Angiolillo DJ, Goodman SG, Bhatt DL, et al. Antithrombotic therapy in patients with atrial fibrillation treated with oral anticoagulation undergoing percutaneous coronary intervention: a north American Perspective-2018 update. Circulation 2018; 138: 527-36.

26. Capodanno D, Huber K, Mehran R, et al. Management of antithrombotic therapy in atrial fibrillation patients undergoing $\mathrm{PCl}$ : JACC state-of-the-art review. J Am Coll Cardiol 2019; 74: 83-99.

27. Eyileten C, Postula M, Jakubik D, et al. Non-vitamin K oral anticoagulants (NOAC) versus vitamin $\mathrm{K}$ antagonists (VKA) for atrial fibrillation with elective or urgent percutaneous coronary intervention: a meta-analysis with a particular focus on combination type. J Clin Med 2020; 9: 1120. 